\title{
VIDA (ZOE), MUNDO E POLÍTICA: UMA REFLEXÃO SOBRE OS ASPECTOS BIOPOLÍTICOS NO PENSAMENTO DE HANNAH ARENDT ${ }^{1}$
}

\author{
Fabio Abreu Passos (UFPI) ${ }^{2}$
}

fabiopassos@ufpi.edu.br

\begin{abstract}
Resumo: Nos últimos anos, a pesquisa em torno do pensamento arendtiano tem buscado explicitar a existência de elementos biopolíticos, mesmo que estes não apareçam no interior de seu pensamento de maneira evidente. Para tanto, se tem procurado, fundamentalmente, em A condição humana, conceitos biopolíticos que colocariam Arendt no rol daqueles que na modernidade lançaram luz sobre a biologização da política e o esvaziamento da esfera pública. Também acreditamos que há, no interior das reflexões arendtianas, elementos biopolíticos. Contudo, nosso objetivo é demonstrar que é na descrição do ponto central da política que está uma das chaves de leitura de uma biopolítica arendtiana. Sustentaremos nossa hipótese a partir da assertiva arendtiana, contida em seu texto O que é Política?, na qual a autora diz que "no ponto central da política está sempre a preocupação com o mundo e não com o homem". Afirmar que o ponto central da política é cuidar do mundo e não dos homens problematiza dois aspectos: o risco que há em não se cuidar do mundo e a compreensão da política enquanto instância preservadora da vida, pois eleger a vida como fundamento da política significa subtrair a liberdade pela necessidade no interior das ações humanas.
\end{abstract}

Palavras-chave: Hannah Arendt; Política; Mundo; Biopolítica; Homem.

\footnotetext{
${ }^{1}$ Recebido em: 23-10-2017/ Aprovado em: 25-03-2018 / Publicado on-line em: 07-08-2018.

${ }^{2}$ Fabio Abreu Passos é Professor da Graduação e da Pós-Graduação em Filosofia da Universidade Federal do Piauí, Teresina, PI, Brasil.
} 


\section{INTRODUÇÃO}

O solo a partir do qual emergirão as nossas reflexões se encontra na assertiva arendtiana, contida em sua obra $\mathrm{O} q u e ́$ Política?, no Fragmento 2b, por meio da qual a pensadora nos adverte que "[...] no ponto central da política está sempre a preocupação com o mundo e não com o homem [...]" (ARENDT, 2006, p. 35). A princípio, essa formulação faz emergir em nós uma perplexidade atroz, pois como não se preocupar com os homens? Como deixá-los entregues à sua própria sorte? Como não criar políticas que procurem solucionar as demandas sociais? Como não se preocupar com as problemáticas humanas da modernidade, que giram em torno das questões referentes à saúde, à moradia, à alimentação e à segurança? Não seriam estas questões fundamentalmente políticas?

A perplexidade começa a ser diluída e, consequentemente, começamos a adentrar o cerne de nossa pesquisa, quando nos voltamos para a compreensão de Hannah Arendt a respeito do mundo. Para ela, o mundo é o artifício humano, uma obra do homo faber ${ }^{3}$, que emerge do solo natural da Terra. Assim, o mundo constitui-se como uma obra das mãos humanas, que perdura de geração a geração, constituindo um lócus imortal para a epifania de seres mortais. É nessa linha de raciocínio que podemos dizer que o mundo sem homens é uma contradição em termos e, portanto, cuidar do mundo é cuidar do espaço privilegiado pa-

\footnotetext{
3 "A fabricação, portanto, define-se como uma atividade produtiva voltada para a construção do entorno não-natural formado pelo conjunto de objetos de uso e artefatos que servem de fronteira entre o mundo feito pelo homem, no qual ocorrem os negócios humanos, e o repetitivo, nãohumano e interminável movimento cíclico da natureza” (NETO, 2012, p. 191).
} 
ra a manifestação da pluralidade humana: a lei da Terra. (ARENDT, 2002, p. 17).

Se o cuidado com o mundo se constitui no ponto central da política, podemos dizer, acertadamente, que o ponto central da política é cuidar para que o lugar da experienciação da pluralidade humana seja preservado e, assim, os homens possam manifestar-se uns aos outros em palavras e ações, demonstrando como os fenômenos mundanos aparecem para cada um em perspectivas que lhes são próprias. Em outras palavras, a pluralidade humana é a condição sine qua non para a manifestação de opiniões, que trazem à luz do público como o mundo aparece para cada homem, dokei moi. Essas opiniões, essa pluralidade de perspectivas, são compreendidas por Hannah Arendt como o fundamento da política, já que são elas que sustentam a possibilidade de resistência, de dissidência, do dissenso. Esteios de verdadeiros corpos políticos republicanos.

Quais são as consequências quando se inverte a afirmação arendtiana e, assim, o ponto central da política passa a ser o cuidado com o homem e não com o mundo? Estaria, nessa inversão ocorrida na modernidade, uma das chaves de leitura que nos permite vislumbrar elementos biopolíticos no interior do pensamento de Hannah Arendt? É na supressão da liberdade pela necessidade, da política pela vida, do mundo pelo consumo que estaria aquilo que se poderia denominar de uma biopolítica arendtiana?

\section{A NECESSIDADE ADENTRA O MUNDO PÚBLICO: QUAIS OS DESDOBRAMENTOS?}

Alguns autores, tal como Odílio Alves Aguiar, vêm se de- 
bruçando sobre as análises acerca da presença do campo de significação do termo biopolítica na obra arendtiana. Nessa perspectiva, Aguiar se posiciona contrário a Giorgio Agamben, filósofo italiano, que não vê nas análises arendtianas sobre o totalitarismo nenhuma perspectiva biopolítica ${ }^{4}$. $\mathrm{Pa}$ ra Aguiar o campo de significação biopolítica pode ser percebido, com mais nitidez, "[...] através das categorias de campo de concentração e da centralidade da atividade do trabalho (labor) no mundo moderno" (AGUIAR, 2012, p. 140). Embora corroboremos com Odílio Alves Aguiar, que vê nas análises de Hannah Arendt sobre os campos de concentração, bem como na vitória do animal laborans ${ }^{5}$, elementos biopolíticos, não será, de maneira direta, essa a via que este trabalho percorrerá. Outro estudioso do pensamento arendtiano, Juan José Fuentes, em seu artigo intitulado Vida, natalidad y liberdad em Hannah Arendt: objeciones a ciertas lecturas biopolíticas del pensamiento arendtiano, por outro lado, aborda a existência de temáticas biopolíticas no pensamento de Hannah Arendt pelo viés da natalidade como um conceito "contra-biológico", o que, segundo o autor, poderia ser tensionado como um elemento que iria de

\footnotetext{
4 "Que a pesquisa de Arendt tenha permanecido praticamente sem seguimento e que Foucault tenha podido abrir suas escavações sobre a biopolítica sem nenhuma referência a ela, é testemunho das dificuldades e resistências que o pensamento deveria superar nesse âmbito. E justamente a essas dificuldades devem-se provavelmente tanto o fato de que, em The Human Condition, a autora curiosamente não estabeleça nenhuma conexão com as penetrantes análises que precedentemente havia dedicado ao poder totalitário (das quais está ausente toda e qualquer perspectiva biopolítica), quanto a circunstância, também singular, de que Foucault jamais tenha deslocado a sua investigação para as áreas por excelência da biopolítica moderna: o campo de concentração e a estrutura dos grandes estados totalitários do Novecentos" (AGAMBEN, 2002, p. 11-12).

${ }^{5}$ Para Odílio, "[...] não faz sentido a afirmação de Agamben, segundo a qual, a análise arendtiana do totalitarismo não está atravessada pela perspectiva biopolítica, bem como não podemos corroborar a assertiva de que inexiste conexão entre A condição humana (1958) e Origens do totalitarismo (1951) (ODÍLIO, 2012, p. 141).
} 
encontro à política enquanto gerenciadora da vida, ou seja, enquanto biopolítica ${ }^{6}$. Esta também aparece aos nossos olhos como uma aposta plausível para se realizar uma análise biopolítica do pensamento de Arendt. Contudo, também não será para essa perspectiva que direcionaremos nossas reflexões.

Outro autor que se volta para a reflexão em torno dos traços biopolíticos presentes no pensamento filosóficopolítico de Hannah Arendt é Iltomar Siviero. Em sua tese de doutoramento intitulada Política e Filosofia no pensamento de Hannah Arendt, mais precisamente no segundo tópico do quarto capítulo, Siviero percorre uma linha argumentativa cujo eixo está centrado no conceito de raça e de que modo o empenho arendtiano em explicitar, em suas bases constitutivas, este conceito deve ser compreendido como uma contribuição à construção de um quadro teórico acerca da biopolítica. Esta contribuição torna-se mais evidente quando nos voltamos para Origens do Totalitarismo, obra em que Arendt debruça-se em pensar acerca da transformação, nos fins do século XIX e início do século XX, da questão do racismo, que passa a fomentar uma disputa política violenta no interior do Imperialismo e sua busca pelo domínio da África a partir de bases biológicas que justificavam a escravidão de negros. Para Arendt, o legado racista desemboca na ideologia alemã da raça, com objetivo de unir o povo alemão contra o domínio estrangeiro, fazendo com que o Imperialismo, nesse sentido, apareça aos olhos arendtianos

\footnotetext{
6 "Para afirmar esta dificultad es necesario defender que la natalidad se revela más bien como un concepto "contra- biológico», o "ultra-biológico", si se nos permite la paradoja" (FUENTES, 2011, p. 242).
} 
como um dos fatores que, ao se cristalizar, levou ao desfecho do totalitarismo, com sua administração do corpo biológico de homens tornados supérfluos.

Contudo, como explicitado, nosso percurso seguirá uma outra via na busca de iluminar a existência de perspectivas biopolíticas na obra arendtiana. Tomaremos a "inversão moderna" do ponto central da política como nosso aporte teórico, a qual nos possibilitará vislumbrar elementos biopolíticos no pensamento da filósofa alemã judia. Assim, a via que percorreremos se aproxima daquela que percorreu o texto de Rodrigo Ribeiro, intitulado Hannah Arendt e a biopolitica: distinção e indistinção entre mundo e vida, no qual o autor procura evidenciar a relevância argumentativa que há na distinção entre mundo e vida no interior do pensamento de Arendt.

Ao seguirmos a esteira argumentativa arendtiana, quando esta nos aponta que o ponto central da política é cuidar do mundo e não dos homens, asserção esta que é invertida na modernidade, procuraremos explicitar que tal inversão se construiu a partir do momento em que a necessidade adentrada o mundo público, levando à supressão da distinção entre os domínios privado e público. A inversão do ponto central da política na perspectiva arendtiana, em nosso entendimento, nos ajuda na tarefa de lançar luz sobre a existência de uma reflexão biopolítica por parte de Hannah Arendt, mesmo que esta nunca tenha se servido do conceito em nenhum de seus escritos. ${ }^{7}$

\footnotetext{
${ }^{7}$ Embora Hannah Arendt não tenha se servido do conceito de "biopolítica" em nenhum de seus escritos, os elementos que, em seu conjunto, fomentam a percepção desse fenômeno político moderno são vislumbrados em várias das obras arendtianas, como nos adverte Francisco Ortega em Cont.
} 
Nessa perspectiva, devemos enfatizar que a categoria da biopolítica tornou-se um dos eixos centrais da filosofia política contemporânea, sobretudo após os estudos de Michel Foucault (1926-1984), o qual cunhou e desdobrou o conceito de biopolítica no interior do seu pensamento filosófico político, conceito este que ganhou publicidade pela primeira vez em uma palestra proferida no Rio de Janeiro, intitulada O nascimento da medicina social, no ano de 1974, sendo sistematizado, entretanto, nas publicações de A vontade de saber (1976) e nos cursos ministrados no Collège de France intitulados Em Defesa da Sociedade (1975-1976), Segurança, Território e População (1977-1978) e Nascimento da Biopolitica (1978-1979). Mas, o que procura descrever, em suas linhas mestras, o conceito de "biopolítica"? Por biopolítica, Michel Foucault compreende as formas de exercício do poder voltadas para o controle e o gerenciamento da vida humana da população em seu sentido meramente biológico, com o objetivo de majorar as

seu artigo Racismo e Biopolítica. Neste artigo, Ortega procura traçar uma linha de aproximação entre Foucault e Arendt acerca das reflexões biopolíticas, tendo como fio condutor o tema do racismo, tema este levado a cabo por Hannah Arendt em boa parte de sua obra Origens do totalitarismo, com desdobramentos conceituais em A condição humana. Nessa perspectiva, para Ortega, "As análises [biopolíticas] arendtianas têm sua continuidade na sua crítica da modernidade em A condição humana, e só através dessa continuidade adquirem seu significado pleno, como um processo de substituição do mundo pela vida, de biologização das esferas da existência, segundo o qual a condição vital destrói as condições mundanas e plurais da existência. Tanto nas sociedades liberais através da vitória do animal laborans -, quanto nas totalitárias, o processo vital invadiu o espaço público e se tornou a regra de organização social. Se no totalitarismo o poder artificialista da técnica era utilizado para reduzir a humanidade ao fato biológico, nas sociedades liberais modernas tornou-se uma 'verdade axiomática' de validade incontestável. O caráter sagrado da vida e a vitória do 'animal laborans' na modernidade estão vinculados ao processo de crescente despolitização, em que a vontade de agir transformou-se 'na passividade mais mortal e estéril que a história jamais conheceu'. O regime biopolítico das sociedades liberais pós-totalitárias se encontra sob o primado da desmesura tecnocientífica, da liberação dos processos vitais, que Arendt define como o 'artificial crescimento do natural”' (ORTEGA, 2001, p. 81). 
forças vitais e aptidões, para que seja produzida uma população útil e dócil. Assim, a política transmuta-se em biopolítica quando a vida humana passa a ser o centro e o cuidado da política.

A biopolítica, enquanto um fenômeno que faz com que compreendamos a política enquanto instrumento de técnicas voltadas para o controle e gerenciamento da vida em seu sentido biológico, nos permite compreender que quando a necessidade adentra a esfera pública, a liberdade sai pela outra via e, assim, a política perde o seu verdadeiro sentido e o ponto central passa a ser o cuidado com o homem, o que faz com que a política se transforme em biopolítica.

Para entendermos a inversão do ponto central da política e a concomitante transformação da política em biopolítica, devemos prioritariamente compreender, em sua orientação, o que vem a ser a epifania da esfera social e o concomitante desaparecimento dos domínios privado e público.

Na obra Condição Humana, publicada no ano de 1958, Hannah Arendt aponta que o "[...] advento do social coincidiu historicamente com a transformação do interesse privado pela propriedade privada em uma preocupação pública” (ARENDT, 2010, p. 83). Ao adentrar a cena pública, o interesse privado exigiu do Estado que este protegesse o acúmulo de riquezas, fazendo com que o interesse público fosse substituído pelo interesse privado e, assim, o Estado passasse a ser um garantidor de que esses interesses não fossem estorvados por nenhum impedimento, pois o interesse privado passa a ser o "interesse de todos". Para Arendt, "[c]omum era somente o governo, nomeado para proteger uns dos outros os proprietários privados na luta 
competitiva por mais riqueza" (ARENDT, 2010, p. 84).

A consequência do surgimento, na cena pública, do interesse pela riqueza, que sai da privatividade dos lares e ganha a publicidade do domínio público, é a ação de minar, em suas bases constitutivas, a durabilidade do mundo, uma vez que as características do acúmulo de riqueza e da durabilidade do mundo são inversamente proporcionais, pois é preciso acumular para consumir. "Sem o processo de acumulação, a riqueza recairia imediatamente no processo oposto de desintegração por meio do uso e do consumo" (ARENDT, 2010, p.84).

Há, portanto, uma subtração dos domínios privado e público na esfera social, o que leva à extinção da diferença entre o público e o privado, bem como o que se passa no interior de cada um desses domínios. O social, nessa perspectiva, aparece aos olhos arendtianos não somente como uma associação de indivíduos, mas como uma esfera híbrida, na qual os assuntos privados passam a interessar a todos e, assim, a necessidade e, conjuntamente, a vida em seu sentido meramente biológico, passam a ser o ponto central das preocupações políticas, uma vez que "[a] necessidade e a vida são tão intimamente aparentadas e conectadas que a própria vida é ameaçada quando se elimina totalmente a necessidade" (ARENDT, 2010, p. 87).

A problemática formulada por Hannah Arendt está embasada no fato de que o que importa, deveras, ao domínio público, não é o espírito empreendedor dos homens, que os leva a querer mais e mais, fazendo com que a roda do processo de acúmulo de riqueza esteja em movimento de maneira ininterrupta, mas a permanência de um mundo comum, capaz de abrigar em seu seio a pluralidade de ho- 
mens que manifestam a cada um como o mundo lhes aparece, uma vez que quanto mais povos, mais mundos, quanto mais povos, mais perspectivas sobre a realidade.

Diante desse movimento que acontece no interior da era moderna, a partir do qual se inaugura o surgimento da esfera social, o domínio híbrido que amalgama as esferas privada e pública, fazendo com que os assuntos de interesse coletivo sejam substituídos pelos interesses privados com "cara" e "jeito" de interesses do todo da sociedade, o que temos diante de nossos olhos é a vida (zoé) apresentando-se como o bem supremo. Para Arendt, "[s]eja como for, a era moderna continua a operar sob a premissa de que a vida, e não o mundo, é o bem supremo do homem" (ARENDT, 2010, p. 398 $)^{8}$. Hoje, não importa a preservação do mundo, espaço comum dos homens, mas proteger a vida, que é o bem supremo.

\section{A REVOLUÇÃO FRANCESA: A VITÓRIA DA NECESSIDADE SOBRE A LIBERDADE}

O reinado da necessidade sobre a liberdade, da vida sobre o mundo, é exemplificado por Hannah Arendt, em sua obra Sobre a Revolução, publicada em 1963, ao dizer o quanto de perniciosidade há quando as demandas sociais adentram

\footnotetext{
8 "Todo esse processo foi potencializado ao máximo quando o trabalho e o consumo se transformaram nos fundamentos de toda relação política, promovendo a vida biológica ao nível de Bem supremo e disseminando o ideal da maior felicidade possível para o maior número de indivíduos em uma sociedade inteiramente formada por detentores de empregos. Imersas no trabalho para a manutenção do seu metabolismo com a natureza, as massas socialmente reconhecidas e economicamente estabelecidas se inserem no ciclo repetitivo de funções vitais, amarrado, por sua vez, ao ciclo da própria reprodução social, isto é, ao cuidado, ao controle e ao desfrute do mero viver. A esfera pública foi destinada a proteger o lado produtivo e social do homem mediante a administração do governo" (NETO, 2012, p. 202).
} 
a arena pública, levando a derrocada do ideal revolucionário, como ocorreu no interior da Revolução Francesa. É fato inconteste que a vida humana está submetida ao poderoso processo da necessidade, que é alimentado pelo movimento contínuo de produção e consumo, o qual sempre fora alojado no interior da privatividade do lar, no qual os homens se refugiavam da forte luz do domínio público para que, protegidos pelas paredes de seu âmbito privado, pudessem recuperar-se das fatigas diárias para, posteriormente, voltar para a esfera pública. Assim, o que se eclipsa na modernidade é a profícua e nítida distinção que havia na Antiguidade clássica entre as esferas privada e pública, na qual a primeira era o lócus da necessária atividade para a manutenção da vida biológica, e a segunda, o espaço da aparição dos homens livres, que se mostravam uns aos outros em fala e ação. Sem essa distinção, o mundo perde sua razão de ser, ou seja, deixa de ser o palco dos assuntos humanos coletivos, e vê-se ameaçado em transformar-se em um amontoado de coisas desconexas ${ }^{9}$. Nesse sentido, o

\footnotetext{
${ }^{9} \mathrm{O}$ mundo, na perspectiva arendtiana, não pode ser definido como a somatória dos objetos físicos, mas refere-se ao conjunto de criações humanas, tais como prédios, monumentos, leis, instituições, artes, os quais permitem que os homens estejam relacionados entre si, ao mesmo tempo em que funciona como uma espécie de delimitador para que suas vidas não venham a se aniquilar mutuamente ao se chocarem umas contras as outras, fazendo com que percam sua identidade individualizante, tal como acontece nas sociedades de massa. Para Arendt, "O domínio público, enquanto mundo comum, reúne-nos na companhia uns dos outros e, contudo, evita que caiamos uns sobre os outros, por assim, dizer. O que torna a sociedade de massas tão difícil de ser suportada não é o número de pessoas envolvidas, ou ao menos não fundamentalmente, mas o fato de que o mundo entre elas perdeu seu poder de congregá-las, relacioná-las e separá-las" (ARENDT, 2010, p. 64). Ainda, nessa perspectiva, segundo André Duarte, "O conceito arendtiano de mundo nada tem que ver com a soma de todos os entes, mas refere-se àquele conjunto de artefatos e de instituições criadas pelos homens, os quais permitem que eles estejam relacionados entre si sem que deixem de estar simultaneamente separados, como se viu anteriormente. Este mundo não se confunde com a Terra ou com a natureza, concebidos como o terreno em que os homens se movem e do qual extraem a matéria com que fabricam coisas, mas diz respeito às barreiras artificiais que os homens interpõem entre si e entre eles e a própria natureza, referindo-se, também, àqueles Cont.
} 
mundo

[...] perderia sua suprema raison d'être se deixasse de ser o palco da ação e do discurso, da teia dos assuntos e relações humanos e das estórias por eles engendradas. Se não fosse ao mesmo tempo abrigo e assunto dos homens, o mundo não seria um artifício humano e sim um amontoado de coisas desconexas ao qual cada indivíduo isolado teria a liberdade de acrescentar mais um objeto (ARENDT, 2010, p. 254).

Para Arendt, foi no interior da Revolução Francesa, ocorrida no século XVIII, que a necessidade, travestida de pobreza, que segundo nossa autora é mais do que privação, pois a pobreza se configura por meio da carência constante e miséria aguda, se apresentou à esfera pública, ameaçandoa. A problemática central da manifestação da pobreza na arena dos negócios públicos está na razão de que "a pobreza é sórdida porque coloca os homens sob o ditame absoluto de seus corpos, isto é, sob o ditame absoluto da necessidade que todos os homens conhecem pela mais íntima experiência e fora de qualquer especulação" (ARENDT, 2011, p. 93). Diante deste quadro, a liberdade teve que se render às forças da necessidade; a permanência do processo vital tomou o lugar da imprevisibilidade, que se constitui como uma das características da ação humana.

Ora, onde a vida está em jogo, toda ação se encontra, por definição, sob o jugo da necessidade, e o âmbito adequado para cuidar das necessidades vitais é a gigantesca e sempre crescente esfera da vida social e econômica, cuja administração tem obscurecido o âmbito político desde os primórdios da época moderna (ARENDT, 2005, p. 202).

assuntos que aparecem e interessam aos humanos quando eles entram em relações políticas uns com os outros" (DUARTE, 2003, p. 10). 
É com a entrada da necessidade no teatro dos negócios humanos que a Revolução Francesa mudaria de rumo e desvirtuar-se-ia de seu mote, uma vez que não visava mais a liberdade, uma vez que seu objetivo principal era a felicidade do povo. Assim, a Revolução Francesa, aos olhos de Hannah Arendt, falhou na instauração da liberdade na forma de um novo corpo político, porque não foi capaz, anteriormente, de sanar as necessidades do processo biológico, batizadas por Arendt de "questão social". Uma vez que liberdade e pobreza são termos não equacionáveis, a miséria fez com que o ideal de liberdade fosse obscurecido. Deste quadro, se depreende que a consequência politicamente mais perniciosa é o fato de que

[...] a vida é o bem supremo, e que o processo vital da sociedade é a própria essência do esforço humano. Assim, o papel da revolução não era mais libertar os homens da opressão de seus semelhantes, e muito menos instaurar a liberdade, e sim, libertar o processo vital da sociedade dos grilhões da escassez, para que ela se convertesse num caudal de abundância. Agora, o objetivo da revolução não era mais a liberdade e sim a abundância (ARENDT, 2011, p. 98).

A relação intrínseca entre o florescimento da miséria na esfera pública e a derrocada da Revolução Francesa e, para o nosso propósito, a derrocada do ponto central da política que é cuidar do mundo e não dos homens, está no fato de que a condição de miséria nunca pode gerar um povo mentalmente livre, uma vez que no estado de miséria, os homens estão presos às necessidades de seu organismo vivo ${ }^{10}$.

\footnotetext{
${ }^{10}$ A razão pela qual, segundo Arendt, a Revolução Americana logrou êxito, ao contrário da Revolução Francesa, "[...] foi que o problema da pobreza estava ausente do cenário americano, mas estava presente em todas as outras partes [...] $\mathrm{O}$ que estava ausente do cenário americano era não tanto a pobreza, e sim a miséria e a indigência, pois 'a controvérsia entre os ricos e os pobres, os Cont.
} 
Para Arendt, a Revolução Francesa abriu os portões da esfera política aos pobres, transformando a esfera pública em esfera social. E o que caracteriza essa nova esfera? Ela é fundada sobre preocupações e cuidados que se referem à esfera doméstica, do lar, os quais não podem ser resolvidos por meios políticos, posto que concernem às temáticas particulares e, nesse sentido, são "[...] questões administrativas, a ser entregues às mãos de especialistas, e não questões passíveis de solucionar com o duplo processo de decisão e persuasão" (ARENDT, 2011, p. 130).

Arendt nos adverte que questões sociais e econômicas já tinham, anteriormente à Revolução Francesa, invadido a esfera pública, mas "[...] com a queda da autoridade política e jurídica e o surgimento da revolução, o foco não eram problemas gerais econômicos e financeiros, e sim o povo, que não simplesmente invadiu, mas irrompeu no domínio político" (ARENDT, 2011, p. 130). A miséria, assim compreendida, aparece como uma força devastadora do verdadeiro ponto central da política, "[...] pois brota e é alimentada pela necessidade da própria vida biológica" (ARENDT, 2011, p. 155), uma vez que seu propósito não é a liberdade, mas a vida e a felicidade a ela atreladas.

Quando a derrocada da autoridade tradicional pôs em marcha os miseráveis da terra, quando eles saíram das sombras de seus infortúnios e afluíram em massa para a praça pública, seu furor pareceu ser

\footnotetext{
laboriosos e os ociosos, os cultos e os ignorantes' ainda estava muito presente naquele cenário e preocupava o espírito dos fundadores, que, apesar da prosperidade do país, estavam convencidos de que essas distinções - 'tão antigas quanto a criação do mundo e tão extensas quanto o globo' eram eternas”. (ARENDT, 2011, p. 103). Assim, diferentemente do que se colocava na pauta das ações revolucionárias na França, na América, "O problema que colocavam não era social, e sim político; referia-se não à ordem da sociedade, e sim à forma de governo" (ARENDT, 2011, p. 103).
} 
tão irresistível quanto o movimento das estrelas, uma torrente se precipitou com força elementar e engolfando um mundo inteiro (ARENDT, 2011, p.155).

A miséria engolfa o mundo inteiro e lhe traz a ameaça de sua ruína, uma vez que é pouco eficiente tentar libertar a humanidade da pobreza, utilizando-se de artifícios políticos; esta tentativa é perigosa, pois a miséria, palavra que em sua etimologia latina (miser) significa infeliz, desafortunado, procurará transformar seu significado interno em seu contrário e, para tanto, quererá consumir tudo que estiver à sua frente, inclusive o mundo. $\mathrm{O}$ trágico resultado da tomada do domínio público pelos desafortunados foi o de que a necessidade fez sucumbir a liberdade e a esfera pública: "[...] a única esfera em que os homens podem ser verdadeiramente livres" (ARENDT, 2011, p. 157), transformouse na esfera do animal laborans.

Diante do exposto, podemos, de maneira explícita, iluminar o cerne de nossa discussão, apontando para o fato de que a derrocada do mundo público em proveito do mundo social, o mundo da necessidade, significou a supressão do lócus da experienciação da liberdade: esta capacidade humana de iniciar novos eventos imprevisíveis e irreversíveis. Nessa perspectiva, se, para Hannah Arendt, "A raison d'être da política é a liberdade, e seu domínio de experiência é a ação" (ARENDT, 2005, p. 192), como efetivar a liberdade $^{11}$ se o domínio público, esfera proeminente da ação

\footnotetext{
${ }^{11}$ Devemos enfatizar que, para Arendt, o homem não possui o dom da liberdade, mas esse é livre somente e tão somente enquanto age, nem antes e nem depois, assertiva esta que culminará na incontestável certeza de que agir e ser livre são a mesma coisa. Arendt, em seu texto O que é liberdade?, faz uma relação entre a atualização da liberdade e a atualização dos princípios correlatos à liberdade. Nesse sentido, para ela, os "[...] os princípios são a honra ou a glória, o amor à igualdaCont.
} 
política, travestiu-se no espaço da necessidade? Em outras palavras, a liberdade só é efetivada no mundo público, no qual palavras e ações de homens plurais são reveladas e, nessa perspectiva, se a ação humana, atividade exercida pela pluralidade, se faz manifesta no espaço público, no mundo comum, o que esperar da política, quando esta sucumbe a interesses particulares? É a inversão do ponto central da política que está em jogo, ou seja, o cuidado com o homem, em seu sentido biológico, e não com o mundo enquanto lugar da epifania da pluralidade humana.

Nesse passo, gostaríamos de enfatizar uma tópica que já fora abordada por nós e que se configura como uma contenda entre Hannah Arendt e seus contestadores. Acreditamos que se tornou explícito o olhar crítico que Arendt tem sobre as questões relacionadas à miséria, fundamentalmente no que tange à sua entrada no cenário político. Quando a esfera pública é tomada de assalto pela miséria, tem-se uma enxurrada de assuntos privados e demandas sociais no espaço que é destinado à fala e à ação em torno de assuntos comuns. $\mathrm{O}$ que há, nessa perspectiva, é um esvaziamento dos temas verdadeiramente políticos, que se referem ao todo e se "decidem" através da deliberação, nascida do confronto entre opiniões divergentes. Mas, diante de tal quadro argumentativo de crítica ao fato de a política se voltar para demandas sociais, o que resta à política? Do que

de, que Montesquieu chamou de virtude, ou a distinção, ou ainda a excelência - o grego aéi aristeúein ('ambicionar sempre fazer o melhor que puder e ser o melhor de todos'), mas também o medo, a desconfiança ou o ódio. A liberdade ou o seu contrário surgem no mundo sempre que tais princípios são atualizados; o surgimento da liberdade, assim como a manifestação de princípios, coincide sempre com o ato em realização. Os homens são livres - diferentemente de possuírem o dom da liberdade - enquanto agem, nem antes, nem depois; pois ser livre e agir são uma mesma coisa" (ARENDT, 2000, p.199). 
trata a política de Arendt? Quais as demandas da política, quais as tópicas que são levadas para o interior do mundo comum?

Essas questões são iluminadas quando nos voltamos para tópicos do diálogo que Hannah Arendt travou com alguns debatedores em torno de sua obra, diálogo este levado a cabo em novembro de 1972, no Canadá. ${ }^{12}$ Nesse debate, entre outros pensadores, estão Mary McCarthy e Richard Bernstein, os quais questionam a Arendt o que se espera que alguém faça na esfera pública, uma vez que as demandas sociais não são propriamente políticas, como apontou Hannah Arendt em Sobre a Revolução? O trecho do debate é extenso, mas para os nossos propósitos é de suma importância transcrevê-lo.

Mary McCarthy: Gostaria de fazer uma pergunta que mantive em minha mente durante bastante tempo. É sobre a distinção bastante acentuada feita por Hannah Arendt entre o político e o social. É particularmente perceptível em seu livro Sobre a revolução, em que ela demonstra, ou busca demonstrar, que o fracasso das revoluções Russa e Francesa deveu-se ao fato de que essas revoluções estavam preocupadas com o sofrimento - em que o sentimento de compaixão desempenhou um grande papel. A Revolução Americana, por sua vez, foi política e terminou na fundação de algo. Mas sempre me perguntei: "O que se espera que alguém faça na cena pública, no espaço público, se ele mesmo não se preocupa com o social? Ou seja, o que resta?". Parece-me que uma vez que temos uma constituição, tivemos a fundação e uma estrutura legal, o cenário para a ação política está lá. E a única coisa que resta a fazer para o homem político é o

12 "Em novembro de 1972 foi organizado no Canadá, pela Sociedade de Toronto para o Estudo do Pensamento Social e Político, um congresso sobre "A obra de Hannah Arendt", patrocinado pela Universidade de York e pelo Canadá Council. Incialmente chamada a participar como convidada de honra, Arendt preferiu participar das discussões. O presente texto foi editado por Melvin A. Hill a partir do que foi recolhido da gravação da discussão" (CORREIA, In: ARENDT, 2010b, p.124). 
que os gregos fizerem: guerrear! Mas isto não pode estar certo! Por outro lado, se todas as questões de economia, bem-estar humano, ocupação, qualquer coisa que afete a esfera social, devem ser excluídas da cena política, então estou perplexa. Fiquei com a guerra e os discursos, mas os discursos não podem ser apenas discursos, têm de ser discursos sobre algo.

Arendt: Você está absolutamente correta, e posso admitir que me faço essa questão. Em primeiro lugar, os gregos não faziam a guerra apenas, Atenas existia antes da Guerra do Peloponeso e o verdadeiro florescimento de Atenas deu-se entre as Guerras Pérsicas e a Guerra do Peloponeso. O que eles faziam então? A vida muda constantemente e as coisas estão constantemente lá como se quisessem ser discutidas. Em todas as épocas as pessoas que vivem juntas terão assuntos que pertencem ao âmbito do público - "são dignas de serem discutidas em público”. O que esses assuntos são em cada momento histórico é provavelmente completamente diferente.

[...]

Richard Bernstein: Mas você sabe muito bem que - ao menos para nós, agora - não se pode fazer de maneira consistente aquela distinção! Embora possamos apreciar a distinção, ambos estão inextricavelmente conectados. Não é o bastante responder à pergunta de Mary McCarthy afirmando que em épocas diferentes temos de examinar com precisão o que adentra a esfera pública. É uma questão de se nos dias de hoje podemos dissociar ou separar consistentemente o social e o político.

Arendt: Acho que está certo. Há coisas em que a medida correta pode ser calculada. Estas coisas podem de fato ser administradas e, desse modo, não estão sujeitas ao debate público. $O$ debate público pode lidar apenas com coisas que - se quisermos formular negativamente - não podemos calcular com exatidão. Caso contrário, se pudermos calcular com certeza, por que nós todos precisaríamos estar juntos? Considere uma assembleia municipal. Há uma discussão, por exemplo, sobre onde colocar a ponte. Isto pode ser decidido de cima ou ser resolvido pelo debate. No caso, há realmente uma questão em aberto acerca de onde é melhor colocar a ponte, que pode ser mais bem decidida pelo debate que de cima para baixo. Assisti certa vez uma assembléia municipal em New Hampshire e fiquei muito impressionada com o nível.

$[\ldots]$ 
Arendt: Consideremos o problema da moradia. O problema social é certamente uma moradia adequada, mas a questão sobre se esta moradia adequada significa integração ou não é certamente uma questão política. Em cada uma destas questões há uma dupla face, e uma destas faces não deve estar sujeita a discussão. Não deveria haver qualquer debate sobre a questão acerca de se todos devem ter uma moradia decente

$[\ldots]$

Arendt: Penso que este exemplo é útil para mostrar concretamente esta dupla face de que eu falei. A questão política é que estas pessoas adoram a região em que vivem e não querem se mudar, mesmos que seja dado mais um banheiro a elas. Esta é de fato uma questão plenamente discutível e um assunto público que deve ser decidido publicamente e não de cima. Mas se é uma questão de quantos metros quadrados cada ser humano precisa para ser capaz de respirar e levar uma vida decente, isto é realmente algo que podemos calcular (ARENDT, 2010b, 138-141).

Essas passagens do debate em muito nos auxiliam para que possamos alcançar o mote do presente trabalho, ou seja, explicitar os elementos biopolíticos presentes na assertiva arendtiana que assinala que o ponto central da política é cuidar do mundo e não do homem. As ponderações de Mary McCarthy e Richard Bernstein feitas a Hannah Arendt estão em consonância com algumas críticas endereçadas à pensadora alemã judia, críticas estas que não compreendem como um pensamento político que esvazia de seu seio as questões mais urgentes das sociedades modernas e contemporâneas pode, em alguma medida, ser fecundo para se pensar os "tempos sombrios" para além do fenômeno totalitário. Não seria Arendt uma pensadora que faz elogios a um modo aristocrático de fazer política? A ação política, em termos arendtianos, não estaria circunscrita a poucos, os não miseráveis? $\mathrm{O}$ que resta a ser discutido em matéria de política, se as questões sociais que assolam mais da me- 
tade do globo não são políticas?

Nas respostas a Mary McCarthy e Richard Bernstein, Arendt, mesmo que de forma simplista e pouco profunda, nos dota com importantes ferramentas argumentativas. Arendt aponta que as questões que adentram o mundo público variam historicamente e, assim, o que não era uma questão política ontem passa a ser um tema político hoje, a exemplo da violência perpetrada contra as mulheres, que de um foro íntimo, da "violência doméstica", passa a ser discutida em espaços públicos, levando a fenômenos políticos como a "marcha das vadias". Além dessa mutabilidade dos assuntos políticos, destacada por Hannah Arendt, uma questão merece uma ênfase maior de nossa parte: para ela, não há dúvida de que questões sociais são de inteira relevância, mas não para a política e sim para a administração, que se configura como uma atividade pré-política, uma vez que lida com questões que não demandam discussão e deliberação: "certamente", "sem sombra de dúvida”, as pessoas merecem ter moradia adequada, saúde de qualidade e educação para todos. Essas demandas sociais são "inquestionáveis" e, assim, estão na esfera da verdade que emudece as opiniões. Contudo, qual o tipo de moradia será preferido pelos moradores de uma determinada cidade: de alvenaria ou de madeira? Qual o método terapêutico será empregado: homeopatia ou alopatia? Qual o método pedagógico mais conveniente: escola nova ou freiriano? $\mathrm{O}$ "modo" como essas últimas problemáticas foram levantadas estariam no rol de temas políticos, visto que demandam discussão, opinião divergente e, posteriormente, o consenso... Ferramentas políticas que necessitam, para serem experienciadas, de um domínio público, de um lugar comum, 


\title{
4. O MUNDO NA PERSPECTIVA ARENDTIANA: OBJETO DE CUIDADO DA POLÍTICA
}

\section{Para descrever, em suas linhas constitutivas, o que vem a ser o mundo para Hannah Arendt ${ }^{14}$, devemos destacar esse ar-}

\begin{abstract}
${ }^{13}$ Acerca do triunfo da necessidade sobre a liberdade, Roberto Espósito, em sua obra Bios, apresenta dois aspectos conflitantes da categoria da liberdade. O primeiro aspecto é aquele que vislumbra a liberdade enquanto crescimento, um desabrochar, uma florescência, levando o autor a concluir que "o conceito de liberdade, no seu núcleo germinal, alude a uma potência conectiva que cresce e se desenvolve segundo a sua lei interna, a uma expansão, a um desdobramento, que junta os seus membros numa dimensão compartilhada" (ESPOSITO, 2010, p. 106). Esse conceito primeiro, apresentado por Esposito, irá se confrontar com a "reconversão negativa que o conceito de liberdade sofre na sua formulação moderna" (ESPOSITO, 2010, p. 106), uma vez que na era moderna a liberdade começa a adquirir um relevo negativo, deixando de ser uma "liberdade do" para se converter em uma "liberdade de". Assim, a modernidade faz da liberdade um domínio do sujeito individual sobre si próprio, concepção esta eminentemente liberal, que a caracteriza de maneira cada vez mais exclusiva: "uma liberdade constituída por aquilo que garante o indivíduo em relação às ingerências alheias através da sua subordinação a uma ordem mais poderosa que o protege. É aqui que tem origem aquela relação antinômica com a esfera da necessidade que acaba por transformar a ideia de liberdade em seu contrário [...]" (ESPOSITO, 2010, p. 109). Assim, os elementos que caracterizam a liberdade na modernidade apresentam-se como "[...] uma consequência directa dela [necessidade]: a necessidade não é, assim, mais do que a modalidade que o sujeito moderno assume como contraponto dialéctico da própria liberdade ou, ainda melhor, da liberdade como livre apropriação do 'próprio'. Assim deve ser interpretada a célebre expressão segundo a qual mesmo acorrentado o sujeito é livre - não apesar mas em razão disso: como efeito autodissolvente de uma liberdade cada vez mais colada à sua crua função autoseguradora" (ESPOSITO, 2010, p. 109).

${ }^{14} \mathrm{Na}$ tese de doutoramento, já podemos antever alguns elementos que seriam desdobrados por Hannah Arendt acerca das características fundantes do mundo. Em O conceito de amor em Santo Agostinho, interroga-se sobre o que seria este mundo, no qual a criatura é introduzida através do seu nascimento, mas que não a determina originariamente. A pergunta a essa questão nos instiga, pois já nessa obra podemos vislumbrar alguns traços do que viria a caracterizar o conceito de mundo em Arendt, como, por exemplo, a distinção entre uma esfera natural (o mundo dado por Deus) e a esfera artificial (mundo criado por mãos humanas). Hannah Arendt vai nos dizer, respondendo à questão acima exposta, que: "Chama-se "mundo", com efeito, não apenas a esta criação de Deus, o céu e a terra [...] mas também todos os habitantes do mundo são chamados 'mundo' [...] Todos aqueles que amam o mundo são chamados "mundo". O mundo, portanto, são aqueles que amam o mundo (dilectores mundi). O conceito de mundo é duplo: por um lado, o mundo é a criação de Deus - o céu e a terra - dada antecipadamente a toda a dilectio mundi, por outro lado, ele é o mundo humano a constituir através do fato de o habitar e de o amar (diligere)" (ARENDT, 1997, p. 79).
\end{abstract}


tifício humano a partir do fato de que este se configura como sendo o lugar da política, uma vez que o mundo é o lugar adequado para a ação e para a palavra. Dizer que o mundo é o lócus da manifestação de ações e palavras, em nosso entendimento, aponta para o fato de que o mundo deve ser tencionado como espaço no qual a pluralidade de homens se faz manifesta, homens estes que devem caracterizar-se como iguais, que não são dominados e que não dominam a partir do subterfúgio da necessidade. Assim, o uso da palavra e da ação não demanda a utilização da violência, mas o convencimento recíproco, no intuito de se alcançar um consenso ${ }^{15}$.

Nesse momento, devemos novamente ressaltar a assertiva que norteia o presente trabalho "o ponto central da política não é cuidar do mundo e não do homem”. Tal afirmação explicita o risco que recai sobre o mundo, quando este, enquanto esfera pública, é inundado por temas sociais, uma vez que, sendo o ponto central da política cuidar do mundo, esse se configura como sendo o lócus da segurança garantidora da imortalidade do fazer e do falar humanos, pois, tratando-se de uma morada imortal de seres mortais, configura-se como um espaço mais seguro para a imortalidade dos agentes que nele transitam, uma vez que as obras de suas mãos permanecem como "coisa mundana"

\footnotetext{
${ }^{15}$ Claude Lefort diz que "para Hannah Arendt, em se tratando do caso da Grécia antiga, o espaço público era assumido como um espaço que estava distante dos assuntos privados, aqueles assuntos próprios ao conceito de oikos, pois ele se refere à unidade doméstica, na qual prevalecem as coerções da divisão do trabalho e das relações entre dominantes e dominados. É nesse espaço público, contrário ao modus vivendi estabelecido no oikos, que os homens reconhecem-se como iguais, bem como discutem e decidem em comum. É também um espaço que os homens, em termos arendtianos, podem rivalizar e procurar por meio de 'belas palavras' e de 'façanhas,' destacar imprimindo a sua imagem na visão e memória públicas” (LEFORT, 1991, p. 69).
} 
de geração em geração. Assim, a esfera pública também é o lugar essencialmente da política, já que é no interior dela que sempre haverá um "palco adequado" para as manifestações de homens em palavras e ações. A esfera pública, nesse sentido, apresenta-se como a condição sine qua non para a formação de opiniões diversas, em torno de temas comuns, bem como para a formulação de consensos. Nesse sentido, segundo Mariângela Nascimento: "A pluralidade é o principal suporte teórico do conceito de esfera pública arendtiano [...]", acrescentando que a esfera pública, no pensamento arendtiano, define-se como "espaço em que os homens se reconhecem não como indivíduos atomizados e depravados, mas como sujeitos coletivos" (NASCIMENTO, In: CORREIA \& NASCIMENTO, 2008, p. 59).

O mundo só o é, na acepção do termo, porque os homens habitam-no e, assim, a alegação arendtiana que norteia nossas reflexões deve ser complementada: "o ponto central da política é cuidar do mundo e não do homem”, pois mundo sem homem é uma contradição em termos. Assim, o mundo sendo o espaço criado por mãos humanas, fomentado para estabilizar a vida dos homens, que deve sobreviver aos ciclos naturais, sendo-lhe uma barreira estável no seio da instabilidade cíclica da natureza, ao ser preservado, cuidado, lança o zelo que lhe é despendido sobre aqueles que nele habitam. Em outras palavras, mundo e homens pertencem-se mutuamente e, por isso, preservar o mundo é preservá-lo para que o plural nele habite, o que nos leva a crer que o principal mote do regime totalitário nazista era destruir o mundo, ao buscar fomentar um único homem de dimensões gigantescas, que visasse o mundo por uma única perspectiva: a da ideologia nazi. 
Contudo, na perspectiva de Hannah Arendt, para que o mundo continue a possuir as características que, em seu conjunto, o constituem, é importante que os homens se voltem para essa criação provinda de suas mãos, no intuito de preservá-la e cuidar dela. E isso somente será possível com o resgate de sentimentos públicos, como o Amor Mun$d i^{16}$. Portanto, o homem se torna mundano, não por estar no mundo somente, mas por se sentir do mundo, ou seja, como alguém que constrói, ajusta, reconstrói, acrescenta estória, preserva estória para as gerações vindouras, que irão povoá-lo: o espaço da convivência plural.

\section{CONSIDERAÇÕES FINAIS: A PRESERVAÇÃO DO MUNDO E} A PRESERVAÇÃO DA MEMÓRIA

A ascensão do social sobre o mundo público e, consequentemente, a inversão do ponto central da política, que deixa de ser o cuidado com o mundo e passa a ser o cuidado com o homem, em sua condição mais elementar de ser vivente, traz consigo consequências devastadoras para o domínio político. Gostaríamos, nesse passo, de destacar duas graves consequências da vitória da necessidade sobre a liberdade, da vida sobre o mundo: o uso da violência e o esquecimento.

As análises arendtianas acerca da violência são construídas, tendo como aporte balizador sua distinção em relação ao poder. $\mathrm{O}$ poder é inerente à existência da comunidade

\footnotetext{
16 “Advindo pela criação a um mundo que lhe é pré-existente, todo homem é necessariamente 'do' mundo, mas só se torna efetivamente mundano a partir do instante em que habita o mundo e ama-o em função de sua própria capacidade fabricadora e desejante" (DUARTE, 2003, p. 4).
} 
política e, sendo assim, ele emerge onde quer que as pessoas se unam na modalidade da ação em concerto. Ainda, o poder não é uma coisa que um indivíduo possui, mas é pertencente a um grupo e existe somente, e tão somente, enquanto esse grupo permanecer unido em torno de uma ação em conjunto. Nessa perspectiva, as características fundantes da violência seriam aquelas diametralmente opostas a estas que apresentamos no que se refere ao poder. Para Arendt, "[...] uma das mais óbvias distinções entre poder e violência é que o poder sempre depende dos números, enquanto a violência, até certo ponto, pode operar sem eles, porque se assenta em implementos" (ARENDT, 2010b, p. 58). Desdobrando esse argumento, e seguindo a trilha de raciocínio arendtiana, podemos dizer que a forma extrema de poder é todos contra um e, inversamente, a forma extrema de violência é um contra todos.

$\bigcirc$ poder, nessa esteira argumentativa, possui seu nascedouro no domínio público, no qual o debate de opiniões acerca de uma problemática comum gerará poder, fruto do consenso. Já a violência, enquanto assentada em implementos, usa-os para calar a divergência, o que faz com que nos atentemos para o fato de que o poder nasce do embate de opiniões pronunciadas em um espaço comum, por homens iguais - que possuem o direito de manifestar como o mundo lhes aparece -; ao contrário, a violência nasce do espaço da desigualdade, no espaço da vida biológica, onde o mais forte, aquele que possui implementos violentos, irá utilizálos para coagir aos demais.

Não é mais eficaz e rentável a utilização da violência em um espaço no qual a liberdade se esvaiu e a preocupação basilar da esfera social é com a manutenção da vida em seu 
sentido biológico? A própria manutenção da vida (zoé) não traz em si um quê de violência, uma vez que uma espécie (biológica) mais forte sobressai sobre a mais fraca? Não seria essa a seleção natural? "A prática da violência, como toda ação, muda o mundo, mas a mudança mais provável é para um mundo mais violento" (ARENDT, 2010b, p. 101), mundo no qual o espaço comum se tornou um deserto no que tange aos interesses comuns. Quem não ama o mundo, ama a sua vida mais do que qualquer outra coisa e, consequentemente, não nutre sentimentos públicos, os quais têm como mote principal a preservação de um espaço no qual a "vitória" se faz pelo melhor argumento, que leva a um consenso, mesmo provisório - uma vez que o consenso é um apaziguamento momentâneo do embate agonístico de opiniões -, que possui como mote a preservação da vida, não a vida biológica, mas a vida plural, pública, política:

Mais uma vez, não sabemos aonde esses desenvolvimentos podem nos conduzir, Mas sabemos, ou deveríamos saber, que cada diminuição no poder é um convite à violência - pelo menos porque aqueles que detêm o poder e o sentem escapar de suas mãos, sejam eles governantes, sejam governados, têm sempre achado difícil resistir à tentação de substituí-lo pela violência (ARENDT, 2010b, p. 108).

Os governos de exceção, a exemplo do totalitarismo nazista e das ditaduras civis militares do Cone Sul, são exemplos claros e notórios da dificuldade de resistir à tentação de substituir o poder pela violência. Para tanto, estes criam um cenário de crise e emergência constante ${ }^{17}$ para que possam suspender as leis, em um ato de exceção, em prol da

\footnotetext{
17 “[...] como não pensar que um sistema que já pode funcionar só com base numa emergência não esteja interessado em mantê-la a qualquer preço?" (AGAMBEN, 2017, p. 135).
} 
segurança da nação, seja para protegê-la da raça judaica, que é vista como um mal que deve ser dizimado, seja dos comunistas: a ameaça vermelha. Assim, na promulgação do estado de exceção, transparecem duas questões que, de fato, amalgamam-se e transformam-se em uma única tópica: a utilização do discurso que pronuncia a verdade, a qual emudece a opinião conflituosa, quando se nomeia o inimigo da nação, bem como a supressão do poder pela violência, quando um (Führer, ou os Militares) se voltam contra todos (judeus e comunistas).

$\mathrm{O}$ movimento exposto acima nos encaminha para o ponto final de nosso percurso reflexivo, a saber, a relação entre o descuido para com o mundo e o surgimento de nações sem passado histórico, ou melhor, sem a consciência de seu passado histórico. Os estados de exceção, que também foram experienciados do outro lado do Atlântico, colocaram boa parte dos países da América Latina sob as espessas e sombrias trevas da violência a partir dos anos 50, ao decretar ditaduras civis militares, impondo sobre essas nações uma confusão semântica: há como ditaduras serem democráticas? A resposta é óbvia: não! Contudo, é exatamente essa áurea de confusão entre os fundamentos de regimes democráticos e de exceção que foi levada a cabo pelas ideologias ditatoriais. No Brasil, por exemplo, havia "eleições" - com o resultado já previsto de antemão -, bem como "oposição" partidária - ARENA x MDB, fenômenos políticos que tinham uma clara intenção: demonstrar para o mundo externo e, principalmente, para o mundo interno, que se estávamos vivendo "tempos de exceção", este só se fazia existente porque havia um propósito maior: "salvar" a democracia de perigos iminentes. 
Os movimentos que buscaram retomar o povoamento do mundo público contra a voz uníssona dos estados de exceção não se efetivaram de maneira homogênea no Cone Sul. Na Argentina, a "Comissão da Verdade" foi instaurada em 1984, um ano após o fim do regime militar. No Chile, os trabalhos da "Comissão da Verdade" começaram em 1991, um ano após o fim da ditadura levada a cabo por Augusto Pinochet. $\mathrm{O}$ resultado desses dois movimentos imediatos ao fim dos regimes de exceção, que procuram colocar os "pingos" nos "is" foi a condenação de 771 pessoas envolvidas com mortes, sequestros e violências cometidas durante os anos de chumbo. ${ }^{18}$

No Brasil, foram necessários vinte e sete anos para se instaurar a "Comissão da Verdade", cujos trabalhos começaram em 2012 e se encerraram em dezembro de 2014. Diante do conteúdo dos relatórios ${ }^{19}$, que viram claros indícios de torturas, mortes e desaparecimento de vários indivíduos durante os anos da repressão, a justiça brasileira nada fez, ou melhor, fez sim: manteve a lei de anistia, o que fez com que todos os indivíduos envolvidos com violências atrozes nem sequer fossem a julgamento. $O$ resultado dessa omissão por parte do poder público brasileiro, no que diz respeito aos crimes cometidos durante os anos da ditadura, é claro: ainda há quem vá para as ruas reivindicar intervenção militar constitucional, ou que faça elogios aos tempos de

\footnotetext{
${ }^{18}$ Sobre esse tema, Cf.: GASPARI, Elio. A Ditadura Envergonhada. São Paulo: Companhia das Letras, 2002 e A Ditadura Escancarada. São Paulo: Companhia das Letras, 2002, bem como REIS, Daniel Aarão. Ditadura e Democracia no Brasil. Rio de Janeiro, Zahar, 2014.

${ }^{19}$ A esse respeito, Cf.: BRASIL, Comissão Nacional da Verdade. Relatório / Comissão Nacional da Verdade. Brasília: CNV, 2014. (Relatório da Comissão Nacional da Verdade; v. 1) e Relatório / Comissão Nacional da Verdade. Brasília: CNV, 2014. (Relatório da Comissão Nacional da Verdade; v. 3).
} 
chumbo, nos quais "vagabundo não andava pelas ruas e os homens de bem podiam viver tranquilamente". Emitir opiniões como essas só é possível em um país que desaprendeu, ou nunca soube, discursar sobre o mundo, sobre as questões de ordem coletiva, fazendo com que o espaço público fosse sempre um deserto árido, sem haver ao menos um oásis. Segundo Arendt,

Se alguém quiser ver e conhecer o mundo tal como ele é "realmente", só poderá fazê-lo se entender o mundo como algo comum a muitos, que está entre eles, separando-os e unindo-os, que se mostra para cada um de maneira diferente e, por conseguinte, só se torna compreensível na medida em que muitos falam sobre ele e trocam suas opiniões, suas perspectivas uns com os outros e uns contra os outros. Só na liberdade do falar um com o outro nasce o mundo sobre o qual se fala, em sua objetividade visível de todos os lados (ARENDT, 2006, p. 60 (Grifos nossos)).

Portanto, para se "entender o mundo como algo comum a muitos", deve-se fazer do mundo algo compreensível, o que se efetivará se muitos homens falarem sobre ele, sobre aquilo que se passa em seu seio. Assim, o "mundo" que nós herdamos pós-ditadura civil militar somente será algo compreensível se falarmos sobre ele e, assim, procurarmos nos reconciliar com nossa realidade que durante vinte e quatro anos esvaziou o falar sobre "nós".

Abstract: In recent years, research on Arendt's thoughts has sought to explain the existence of biopolitical elements, even if they do not appear inside of her thoughts in a so evidently way. To do so, researchers have been looking for, essentially, in The human condition, biopolitical concepts that would put Arendt in the list of those who in modern times have launched light on the biologization of politics and the draining of the public sphere. We also believe that there is, within Arendt's reflections, biopolitical elements. However, our objective is to demonstrate that it is in the description of the central point of politics that there is one of reading keys to Arendt's biopolitical issues. We will sustain our hypothesis based on the Arendt's assertive, that is 
contained in your text What is politics?, in which the author says that "at the center point of politics there is always a concern with the world and not with man". Saying that the central point of politics is to take care of the world and not of men discusses two aspects: the existent risk of not taking care of the world and, the understanding of politics as an instance of life preservation, since electing life as the foundation of politics means subtracting the freedom for necessity in of human actions.

Keywords: Hannah Arendt; care with the world; biopolitics; human superfluity.

\section{REFERÊNCIAS}

AGAMBEN, Giorgio. Homo Sacer: o poder soberano e a vida nua I. Trad. Henrique Burigo. Belo Horizonte: Editora UFMG, 2002.

. O uso dos corpos. Trad. Silvino J. Assmann. São Paulo: Boitempo, 2017.

AGUIAR, Odílio Alves. A recepção biopolítica da obra de Hannah Arendt Conjectura, Caxias do Sul, v. 17, n. 1, p. 139-158, jan./abr. 2012.

ARENDT, Hannah. A Condição Humana. Trad. Roberto Raposo. Revisão e Apresentação Adriano Correia. $11^{\mathrm{a}} \mathrm{ed}$. Rio de Janeiro: Forense Universitária, 2010.

- A vida do espírito: o Pensar, o Querer e o Julgar. Trad. Antônio Abranches e Helena Martins. Rio de Janeiro: Relume Dumará, 2000.

. Entre o Passado e o Futuro. Trad. Barbosa. São Paulo: Perspectiva, 1997.

- O que é Política?: Fragmentos das obras póstumas compiladas por Ursula Ludz. Trad. Reinaldo Guarany. $6^{\mathrm{a}}$ 
ed. Rio de Janeiro: Bertrand Brasil, 2006.

- Sobre a Revolução. Trad. Denise Bottmann. São Paulo: Companhia das Letras, 2011.

. Sobre Hannah Arendt. Trad. Adriano Correia. Inquietude, Goiânia, vol. 1, n 2, ago/dez - 2010.

. Sobre a violência. Trad. André Duarte. $2^{\mathrm{a}}$ Ed. Rio de Janeiro: Civilização Brasileira, 2010b.

BRASIL, Comissão Nacional da Verdade. Relatório / Comissão Nacional da Verdade. Brasília: CNV, 2014. (Relatório da Comissão Nacional da Verdade; v. 1).

- Relatório / Comissão Nacional da Verdade. Brasília: CNV, 2014. (Relatório da Comissão Nacional da Verdade; v. 3).

CORREIA, Adriano. NASCIMENTO, Mariangela (Orgs.). Hannah Arendt: Entre o Passado e o Futuro. Juiz de Fora: UFJF, 2008.

DUARTE, André. Hannah Arendt e o pensamento político sob o signo do Amor Mundi. From the Selected Works of Andre Macedo Duarte. Disponível em: http://works.bepress.com/andre duarte/25, January 2003.

FUENTES, Juan José. Vida, natalidad y libertad en Hannah Arendt: Objeciones a ciertas lecturas biopolíticas del pensamiento arendtiano. ISEGORÍA. Revista de Filosofía Moral y Política, N. ${ }^{\circ} 44$, enero-junio, 2011, 239-255.

ESPOSITO, Roberto. Bios - biopolítica e filosofia. Trad. M. Freitas da Costa. Lisboa: Edições 70, 2010. 
LEFORT, Claude. Pensando o Político: ensaios sobre democracia, revolução e liberdade. Trad. Eliana M. Souza. Rio de Janeiro: Paz e Terra, 1991.

NETO, Rodrigo Ribeiro Alves. Hannah Arendt e a biopolítica: distinção e indistinção entre mundo e vida. Princípios - Revista de Filosofia. Natal (RN), v. 19, n. 31 Janeiro/Junho de 2012, p. 181-207.

ORTEGA, Francisco. Racismo e Biopolítica. In: AGUIAR et al (Org.). Origens do Totalitarismo: 50 anos. Rio de Janeiro: Relume Dumará, 2001.

SIVIEIRO, Iltomar. Política e Filosofia no pensamento de Hannah Arendt: aproximações críticas desde a memória dos acontecimentos políticos. São Leopoldo: UNISINOS, 2016 (Tese de Doutoramento). 